\title{
Lobomycosis-like disease in wild bottlenose dolphins Tursiops truncatus of Laguna, southern Brazil: monitoring of a progressive case
}

\author{
Fábio G. Daura-Jorge ${ }^{1,2, *}$, Paulo C. Simões-Lopes ${ }^{1}$ \\ ${ }^{1}$ Departamento de Ecologia e Zoologia, Universidade Federal de Santa Catarina, Florianópolis, Santa Catarina, 88040-900, Brazil \\ ${ }^{2}$ Curso de Pós-Graduação em Zoologia, Universidade Federal do Paraná, Curitiba, Paraná, Brazil
}

\begin{abstract}
Lobomycosis is a chronic dermal infection affecting humans and small cetaceans. In 1993, a study identified the presence of the etiologic agent of lobomycosis in a resident population of Tursiops truncatus (bottlenose dolphin) in Laguna, Brazil. Until now, no additional information relating to the persistence or prevalence of this pathogen in this population has been available. Numbering less than 60 animals, the residency of these dolphins in an impacted lagoon system has raised concerns about the health and viability of this small population. Using photo-identification data collected between September 2007 and September 2009, this study evaluated the occurrence of lobomycosis-like disease (LLD) throughout this population. Of 47 adult dolphins and 10 calves identified, 7 $(12 \%)$ presented some form of epidermal lesion and $5(9 \%)$ had evidence of LLD. The lesions were stable in all but 2 cases, in which a progressive development was recorded in a presumed adult female and her calf (referred to here as the LLD pair). During the first few months of observation, the lesion grew slowly and at a constant rate on the adult. However, in the fourteenth month, the growth rate increased rapidly and the first lesions appeared on the calf. Compared to the rest of the population, the LLD pair also presented a different spatial ranging pattern, suggesting a possible social or geographic factor. Current and previous records of LLD or lobomycosis indicate that the disease is endemic in this population. These findings highlight the importance of monitoring both the health of these cetaceans and the quality of their habitat.
\end{abstract}

KEY WORDS: Tursiops truncatus $\cdot$ Lobomycosis $\cdot$ Progressive case $\cdot$ Skin diseases $\cdot$ Pathologies

\section{INTRODUCTION}

Epidermal lesions have been reported in several cetacean species and can be caused by viruses, bacteria, protozoans or fungi (Wilson et al. 1997, Van Bressem et al. 2008). In recent years, the incidence of lesions caused by skin diseases has increased, possibly due to the raised exposure of some populations to environmental stressors of both natural and anthropogenic origin (Wilson et al. 1999, Reif et al. 2006, Van Bressem et al. 2009).

Lobomycosis (lacaziosis), a chronic dermal infection caused by the fungus Lacazia loboi (Taborda et al. 1999) (syn. Loboa loboi; Caldwell et al. 1975), stands out as a frequently reported skin disease in small cetaceans in some tropical and subtropical regions. The infection process is still unknown, but a local trauma can be the gateway for the etiologic agent (Rodriguez-Toro 1993, Dierauf \& Gulland 2001). In Delphinidae, cases of lobomycosis appear to be significantly associated with disorders of the adaptive immune system, which may be related to chronic exposure to chemical and biological pollutants (Reif et al. 2009). Additionally, specific salinity and water temperature conditions seem to influence the infection process (Reif et al. 2006). Lobomycosis lesions are usually found throughout the body surface as cutaneous nodules or rashes of more than $30 \mathrm{~cm}$ in diameter. These 
lesions may be smooth or verrucous, with occasional ulcerations (Reif et al. 2006).

Lobomycosis, or lobomycosis-like disease (LLD) in the absence of a histological diagnosis, has been reported in 3 species of small cetacean-Tursiops truncatus, T. aduncus and Sotalia guianensis-in various parts of the world (e.g. Migaki et al. 1971, Caldwell et al. 1975, Van Bressem et al. 2007, 2009, Kiszka et al. 2009). It is also a known endemic disease affecting the human populations of the Amazon region (RodriguezToro 1993). The epidermal lesions presented by cetaceans are similar to those observed in humans, though there is a subtle morphological difference in the etiologic agent itself (Haubold et al. 2000). In addition, reports of the occurrence of the disease in Delphinidae extend beyond the endemic limits observed in human populations (Dierauf \& Gulland 2001), with the first records in the bottlenose dolphin occurring along the Florida coast in the 1970s (Caldwell et al. 1975, Haubold et al. 2000). Subsequently, cases were described in Europe (Migaki et al. 1971), the Texas coast (Cowan 1993) and South America, including Venezuela, Colombia, Ecuador, Peru and southern Brazil (Simões-Lopes et al. 1993, Moreno et al. 2008, Bermudez et al. 2009, Van Bressem et al. 2009), where recent reports are not uncommon.

The bottlenose dolphin Tursiops truncatus is often observed in coastal waters along the Santa Catarina State coast, in southern Brazil (Simões-Lopes \& Ximenez 1993). One small population of approximately 55 individuals has a high degree of residence in lagoons near the town of Laguna (Simões-Lopes \& Fabian 1999, Simões-Lopes \& Daura-Jorge 2008). Some individuals of this population (approximately $40 \%$ ) engage in a singular and ritualized behavior of cooperative interaction with artisanal fishermen (for details of this interaction see Simões-Lopes et al. 1998). Bottlenose dolphins resident in this lagoon system are potentially exposed to multiple environmental stressors. The lagoons are bordered by urban areas which are a source of anthropogenic contamination. Largescale production of shrimp and rice may also contribute to additional input of both chemical and biological contaminants (Scherer et al. 2006). Moreover, the area also receives waste from nearby power plants and coal mining operations, pottery production and adjacent pig farming (Lima et al. 2001).

The first recorded case of lobomycosis in southern Brazil occurred in the Tursiops truncatus population of Laguna in the early 1990s. A female was found dead with several verrucoid cutaneous lesions, concentrated on the flanks and ventral portion of the body, and histological tests confirmed the presence of Lacazia loboi (Simões-Lopes et al. 1993). Despite the record of lobomycosis nearly $20 \mathrm{yr}$ ago, the persistence, severity and endemicity of the disease in this bottlenose dolphin population remained unknown. Therefore, this study aimed to re-evaluate and describe the occurrence of skin lesions similar to lobomycosis (visually diagnosed and termed LLD, lobomycosis-like disease) throughout the Laguna population of bottlenose dolphins. We determined the prevalence of LLD in the population and present here the progression of a case which affected a presumed adult female and her calf. Previously, lobomycosis has typically been diagnosed in dead or captive animals, but recent success of visual diagnosis (e.g. Van Bressem et al. 2007, Moreno et al. 2008, Murdoch et al. 2008, Burdett Hart et al. 2010) and the Laguna area's previous record of the disease (Simões-Lopes et al. 1993), offered a critical opportunity to monitor the progress of probable cases of lobomycosis in the natural environment.

\section{MATERIALS AND METHODS}

Study area. Adjacent to the town of Laguna $\left(28^{\circ} 30^{\prime} \mathrm{S}, 48^{\circ} 50^{\prime} \mathrm{W}\right)$ is one of the largest lagoon complexes in southern Brazil, a coastal system covering approximately $300 \mathrm{~km}^{2}$ and consisting of 3 subunits: the Mirim, Imaruí and St. Antônio lagoons (Fig. 1). The northern and innermost portion of the system is the Mirim Lagoon, dominated by rice farms. The Imaruí Lagoon forms the central portion, with a high concen-

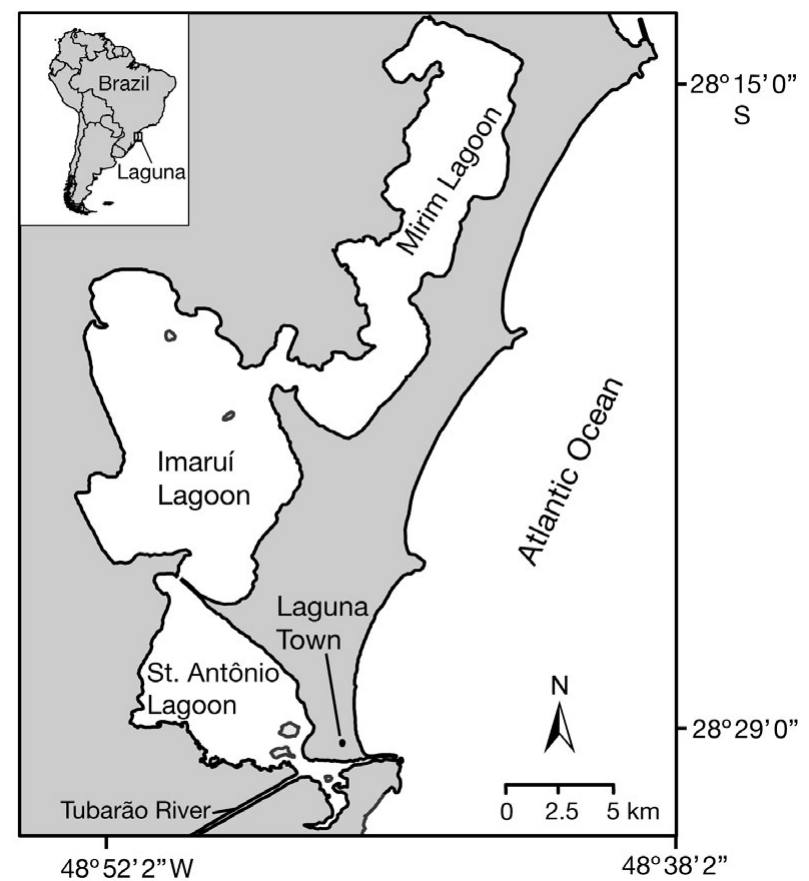

Fig. 1. Study site. St. Antônio Lagoon, Imaruí Lagoon, Mirim Lagoon and Tubarão River in southern Brazil 
tration of shrimp farms. The southern portion, the St. Antônio Lagoon, is the most urbanized and is fed by the Tubarão River, which runs near the coal fields of southern Santa Catarina State. In general, all lagoons are shallow, with an average depth of approximately $2 \mathrm{~m}$, with the exception of the deep connection channels to the ocean (Meurer \& Netto 2007). Where not urbanized or modified, the lagoon margins consist of wetlands and freshwater marshes, or small beaches and rocky shores. No studies have so far described the quality of the local habitat.

Data collection. Between September 2007 and September 2009, the bottlenose dolphin population of Laguna was monitored via weekly photo-identification surveys. These survey data were primarily used to estimate population size and describe ranging behavior. A small boat ( $5 \mathrm{~m}$ with $15 \mathrm{hp}$ outboard engine) was used to cover pre-defined routes to sample the area evenly. Observation was concentrated in the southern and central lagoons, with the Mirim Lagoon visited only occasionally. Sampling occurred only under favorable light, wind and sea conditions (not exceeding Beaufort 2).

When a group of dolphins was detected it was followed for a period of $20 \mathrm{~min}$, during which time we noted the geographic location, group size, presence of calves, occurrence of interaction between dolphins and fishermen, and other information. Focal group sampling methods were used, in which a group of individuals is the focus of observations (Lehner 1996). Calves were identified on the basis of body size and a strong association behavior with the possible mother (Mann et al. 2000).

Photo-identification of natural markings was used to identify and catalog individuals (Würsig \& Jefferson 1990). As many photos as possible were taken while observing each group to ensure that all individuals were photographed. The high-quality photographs also enabled the identification and measurement of dermal skin lesions on the flanks of identified animals.

Data analysis. Photos showing individuals with epidermal lesions were separated for analysis. Two types of epidermal lesion were defined: lesions similar to lobomycosis (LLD), and lesions unlike LLD. To identify LLD lesions we used the case described by SimõesLopes et al. (1993). Two individuals with LLD (called here the LLD pair), consisting of 1 presumed adult female (L19) and her accompanying calf (L25), were selected to assess the progression of a specific lesion.

We used Photoshop CS4 (Adobe) and ArcGIS 9.2 (ESRI) software to map and measure the relative size and progress of the adult female's lesion. We selected only high-quality photographs with satisfactory brightness and focus, angle of the dorsal fin orientated in parallel (at or close to $90^{\circ}$ ), and occupying a large proportion of the frame. Only the right side with the target lesion and the best image from each sighting was analyzed. With the magnetic pen tool of Adobe Photoshop the images of the dorsal fin and the target lesion were extracted from the background and the base of the dorsal fin was adjusted to a horizontal position. The lower base was defined by the insertion points indicated by the more prominent crease in both anterior and posterior dorsal fin margin. The lesion contour followed the darker color of the nodule that surrounds the white verrucoid lesion, and then the normal skin was excluded for the lesion area calculation (see Fig. 4). Once extracted, the images were imported into the same project view in ArcGIS 9.2. For each image a polygon contour of the dorsal fin and its respective lesion was drawn. The area of each polygon was estimated using the 'measure polygon feature' tool of ArcGIS 9.2. Since the aim of this approach was to measure the proportion of the lesion in relation to the dorsal fin, we did not take into account any unit or coordinates in ArcGIS. Inaccuracies caused by different distances and angles were minimized by using images of the dorsal fin and lesion extracted from the same photograph. In this way, any variations in distance, angle or any other feature had the same effect on measurements of the dorsal fin and the lesion.

The relative size of the lesion was calculated from the proportion $(P) A_{\text {lesion }} / A_{\text {dorsal }} \times 100$, in which $A_{\text {lesion }}$ is the estimated area of the lesion, and $A_{\text {dorsal }}$ is the area of the dorsal fin. As the re-sighting of the LLD pair was a chance event, the intervals between re-sighting varied. Thus, the growth rate per day of the skin lesion was estimated for each interval that elapsed between photos by: $\left[\left(P_{X+1}-P_{X}\right) / t_{\text {int }}\right] \times 10$, in which $P_{X+1}$ is the proportion at time $x+1, P_{X}$ is the proportion at time $x$, and $t_{\text {int }}$ is the number of days in the interval between $x$ and $x+1$.

The home range, defined here as 'the area used by an individual for vital activities in the studied area' (adapted from Burt 1943), of each individual identified in the population, including the LLD pair, was determined via the Fixed Kernel method (Worton 1989) using the extension Hawth's Analysis Tools (Beyer 2004) for ArcGIS9.2 (ESRI). We used the Kernel contour line of $95 \%$ for estimates of home ranges, and a contour line of $50 \%$ for core area estimates (Powell 2000). The individual encounter rate was calculated on the basis of the proportion of days on which an individual was sighted from the total number of survey days. The prevalence of lesions in the population was defined as the proportion of photo-identified individuals with epidermal lesions. The prevalence of LLD was defined as the proportion of individuals with lesions similar to lobomycosis. 

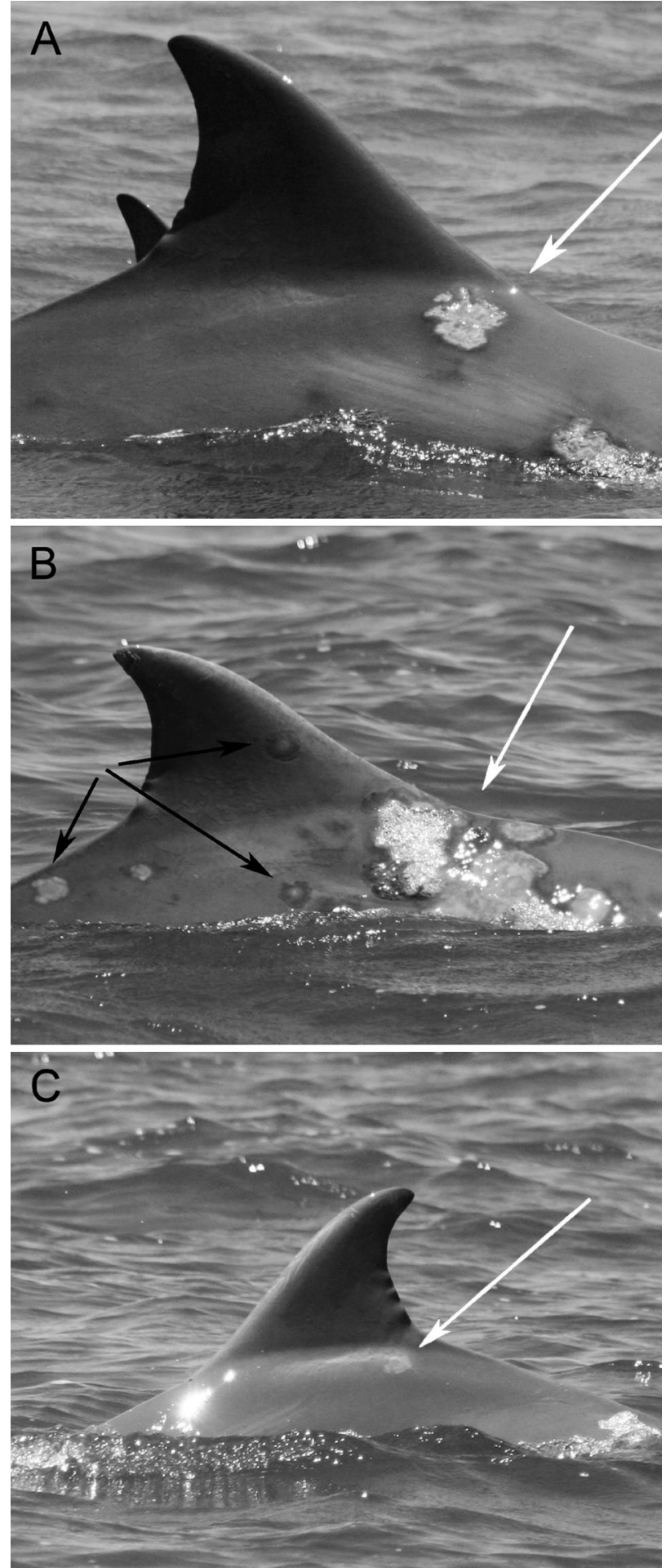

Fig. 2. Tursiops truncatus. (A,B) Progress of lobomycosis-like disease (LLD) in adult female L19, and (C) the emergence of LLD in calf L25 during the sampling interval of 14 mo. The appearance of black nodules preceded lesion eruption in L19 (black arrows). White lesions appeared after 14 mo (437 d) in L25 (white arrow). (A) November 8, 2007 - Day 20; (B,C) January 8, 2009 - Day 455

\section{RESULTS}

The sampling period totaled 102 field days over an interval of $22 \mathrm{mo}$, with $470 \mathrm{~h}$ of direct observation and approximately 10000 pictures taken. We cataloged 47 presumed adults and 10 calves. Epidermal lesions were present in $12 \%(\mathrm{n}=7)$ of photo-identified dolphins, and $9 \%(\mathrm{n}=5)$ had lesions similar to lobomycosis (LLD), with several verrucoid and white lesions along the dorsal surface (Fig. 2). This prevalence (9\%) was statistically equal ( $\mathrm{p}>0.05$, Fisher's exact test) to that observed for populations of Tursiops truncatus in Florida (values from Reif et al. 2006, Murdoch et al. 2008) and T. aduncus in the Indian Ocean (values from Kiszka et al. 2009). The other lesions presented as white or dark patches but were non-verrucoid.

The population's spatial distribution was heterogeneous across the area; the St. Antônio Lagoon was used more intensively, particularly the areas around the Tubarão River delta and the channel connecting the lagoon to the sea (Fig. 3). The spatial pattern of the LLD pair differed from that of the distribution of the overall population. There was no spatial overlap between the core area estimated for the LLD pair and the core area estimated for the overall population (Fig. 3). The LLD pair used the more internal areas, the Imaruí and Mirim Lagoons, and had a low encounter

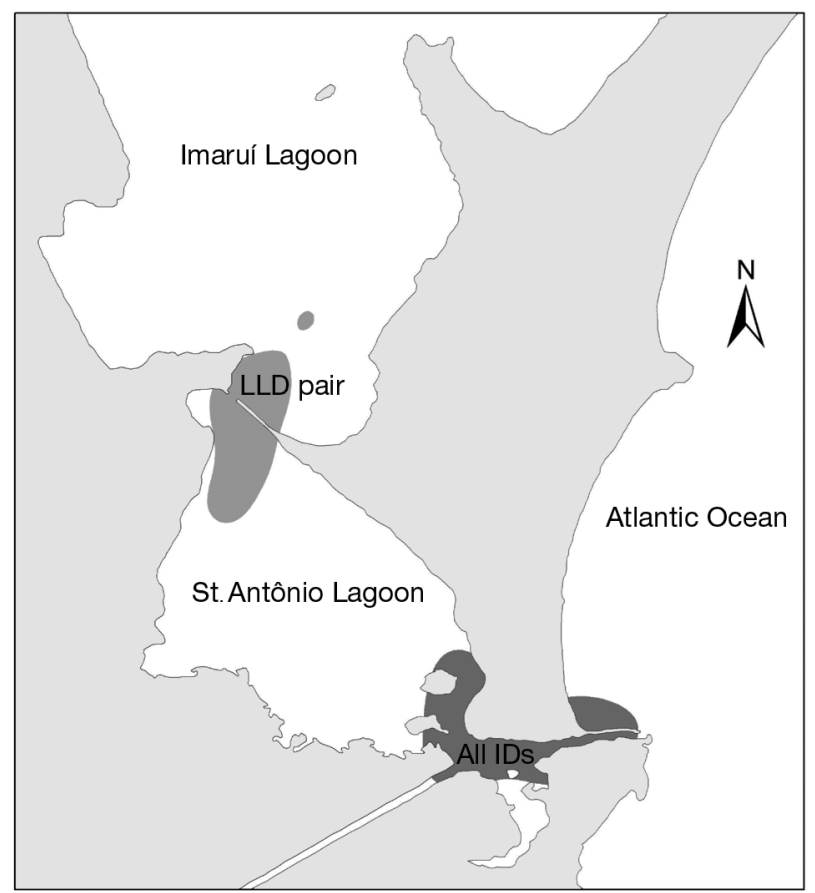

Fig. 3. Tursiops truncatus. Comparison between the core area (kernel method $50 \%$ ) of the total population (All IDs, excluding the LLD pair; dark gray) and of the LLD pair (L19 and L25; mid-gray) 
rate $(17 \%)$ compared to the other dolphins (approximately $29 \%)$. In 8 of 12 (67\%) sightings, the LLD pair was isolated from all other individuals; when observed in association with another group they remained in a peripheral position. Though other dolphins with LLD interacted cooperatively with artisanal fishermen, at no time was the LLD pair observed to interact.

The LLD pair (L19 and L25) was monitored over $14 \mathrm{mo}$, during which time the progressive development of the lesion was recorded. In other LLD cases, lesions remained stable; no individuals showed regression of any lesions. A lesion anterior to the dorsal fin on the right side was noted in the first observation of the adult female (L19) and increased considerably in area during the course of the study, connecting to other lesions on the right flank, near the pectoral fin (Fig. 2A,B). We also noticed the appearance of multiple white patches throughout the body, preceding the appearance of black nodules that culminated in the eruption of a verrucous lesion (Fig. 2B). During the first year, the calf (L25) showed no signs of any skin lesions; after 14 mo (428 d) the first lesions were identified on its back (Fig. 2C).

The progress of the lesion, based on the proportion of its area relative to the area of the dorsal fin, followed a trend of continuous and linear increase (Figs. 4 \& $5 \mathrm{~A})$. The estimated growth rate did not vary over the first 13 mo, confirming constant progression. However, in the interval between the last 2 sightings, between Day 428 and Day 455 (Fig. 4E,F), the lesion increased

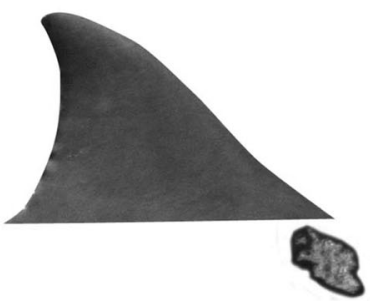

A: 10/19/07 - Day 1

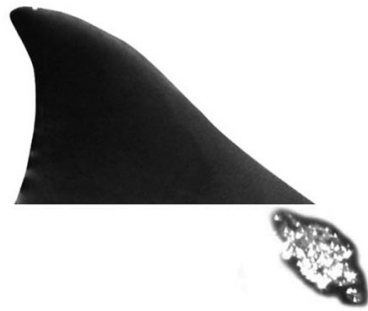

D: 04/05/08 - Day 198

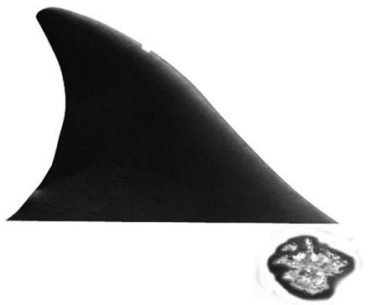

B: $11 / 08 / 07$ - Day 20

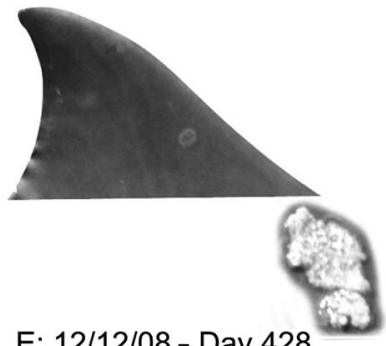

E: $12 / 12 / 08$ - Day 428

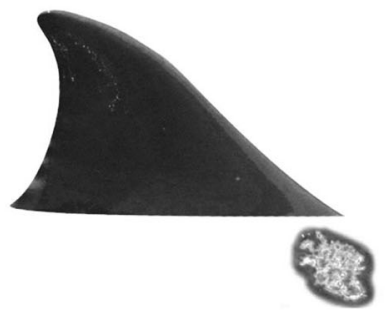

C: $12 / 21 / 07$ - Day 62

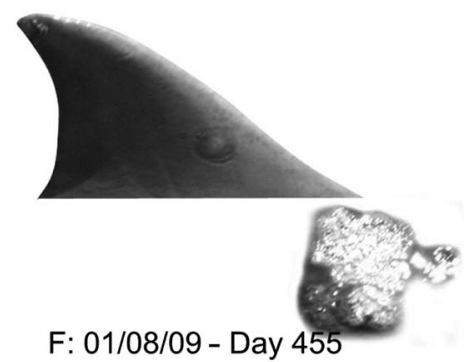

Fig. 4. Tursiops truncatus. Increase in lesion size relative to dorsal fin size in adult female L19 over the sampling interval of $14 \mathrm{mo}$. Dates are mo/d/yr
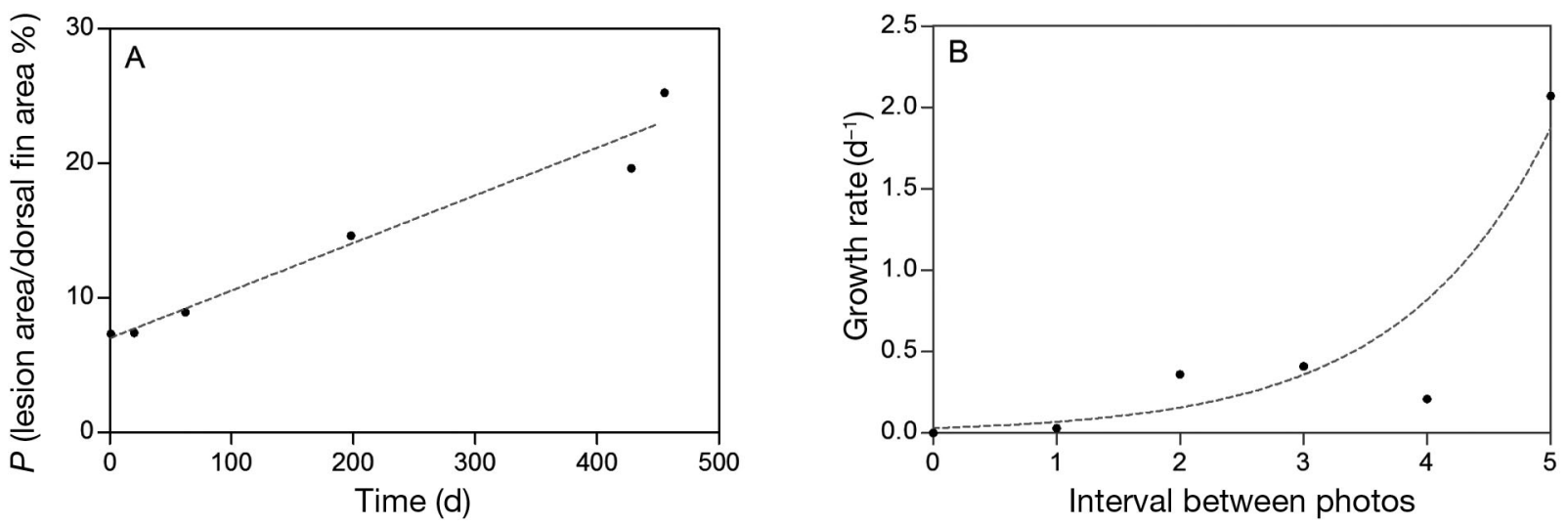

Fig. 5. (A) Proportion $(P, \%)$ of the lesion area compared to the dorsal fin area of adult female L19, and (B) lesion growth rate per day for each interval between photos. Growth rate is expressed as the change in area of the lesion in relation to the total dorsal fin area per unit time (number of days elapsed between photos) 
markedly, with a growth rate much higher than in the previous periods, suggesting an exponential growth rate for this case (Fig. 5B).

The accelerated progress of the target lesion in the last period coincides with the identification of the first lesions in the calf (L25), a merging of the target lesion with adjacent lesions, and an abrupt appearance of new nodules and white patches across the back of individual L19 (Figs. 2 \& 4). After this observation, on January 8,2009 , the LLD pair was not encountered again during the last 8 mo of systematic monitoring.

\section{DISCUSSION}

The description of the skin lesions observed in this study is consistent with those observed and histologically diagnosed as lobomycosis by Simões-Lopes et al. (1993) in the same resident population of Tursiops truncatus in Laguna. Therefore, we strongly suppose that the lesions reported here are cases of lobomycosis, indicating the persistence of the disease in this dolphin population for at least 15 yr. The prevalence level of LLD reported by the present study $(9 \%)$ is comparable to that observed for other bottlenose dolphin populations (Reif et al. 2006, Murdoch et al. 2008, Kiszka et al. 2009). Nevertheless, LLD may actually be more prevalent than estimated by current methods, as only dorsal lesions can be easily observed from the surface (Murdoch et al. 2008).

In recent years, the occurrence of lobomycosis has been noticed in many coastal populations of small cetaceans (Bermudez et al. 2009, Rotstein et al. 2009, Van Bressem et al. 2009). In addition to the first report in southern Brazil (Simões-Lopes et al. 1993), recent cases of lobomycosis have been confirmed for Tursiops truncatus in the Tramandaí estuary, about $300 \mathrm{~km}$ south of Laguna (Van Bressem et al. 2007, Moreno et al. 2008, Paniz-Mondolfi \& Sander-Hoffman 2009). It is important to note that long-distance movements and the exchange of a few individuals between Laguna and Tramandaí have been recorded (Simões-Lopes et al. 1998, Simões-Lopes \& Fabian 1999), allowing at least 2 hypotheses: a transmission between individuals or similar environmental exposures. About $120 \mathrm{~km}$ to the north, epidermal lesions have been observed in $T$. truncatus from Norte Bay, Santa Catarina Island (Flores et al. 2005), and we have recently observed 2 adult bottlenose dolphins with LLD in the Sul Bay of Santa Catarina as well (F. G. Daura-Jorge pers. obs.). LLD has also been described in a population of Sotalia guianensis in the Paranaguá estuary, about $220 \mathrm{~km}$ to the north (Van Bressem et al. 2009). Overall, these reports suggest that LLD is not uncommon in populations of small cetaceans in southern Brazil, indicating an endemicity of lobomycosis in the region.
Calves with LLD were also found in the Paranaguá population of Sotalia guianensis in southern Brazil (Van Bressem et al. 2007) and in the Indian Ocean population of Tursiops aduncus (Kiszka et al. 2009). Little is known about the mechanism of LLD transmission and, in general, fungal infections are not contagious between individuals (Geraci \& Ridgway 1991). Thus, the manifestation of LLD in the calf (L25) is not sufficient to support the notion of transmission from the mother. However, it indicates that both animals were probably exposed to the same pathogen or to the environmental stressors that could have changed their immune status. Despite the very low risk of zoonosis involving this pathogen (Symmers 1983), the proximity of fishermen and dolphins in Laguna requires attention. Lobomycosis has been observed for both humans and dolphins in South America (Venezuela) by Bermudez et al. (2009), who suggest that, although there is no demonstrable relationship between the 2 cases, the presence of Larazia loboi in the dolphin population exposes local human communities to this etiologic agent. There is no report of lobomycosis in humans in Laguna; however, the cases in dolphins indicate that the pathogen is present in the area and that there is a potential exposure of local human communities.

Individual L19 showed progressive lesions during the monitoring. Initially, nodular and dark patches appeared, later flaking and forming white lesions. The white lesions led to verrucous eruptions that continually increased in diameter until joining with adjacent lesions. In general, lobomycosis is considered to be a slowly progressing disease with a gradual decrease in growth rate over time (Kiszka et al. 2009, Burdett Hart et al. 2010). However, in this case we observed an abrupt increase in lesion progression after approximately 14 mo of monitoring. The target lesion of dolphin L19 increased by almost 30\% in a short period of time (about $30 \mathrm{~d}$ ) and new lesions appeared along the back. This abrupt progression suggests a possible change in immune status of L19. However, without additional evidence we cannot associate this with the following disappearance (or death) of the LLD pair (L19 and L25).

The emergence of LLD or other epidermal lesions in populations of small cetaceans is usually associated with chemical and/or biological contamination of habitat (Van Bressem et al. 2007, 2009, Bearzi et al. 2009, Kiszka et al. 2009), which apparently alters the response of the adaptive immune system of individuals in the population and increases susceptibility to opportunistic mycoses (Reif et al. 2009). The main habitat contaminants frequently mentioned are trace metals, polychlorinated biphenyls (PCBs), dichloro-diphenyltrichloroethane (DDT) and polycyclic aromatic hydrocarbons (PAHs) (Lahvis et al. 1995, Ross 2002). The 
LLD pair showed a social and spatial pattern which differed from the rest of the population, and this deviant behavior could be related to the severity of the disease or to a physiologic stress condition (Constantine 2001). The area used more intensively by the LLD pair - the north-central portion of the study area-is more exposed to multiple contamination sources, such as those from shrimp and rice farms, and shows the lowest levels of salinity and water circulation (Meurer \& Netto 2007). These factors could be relevant indirectly to the development of lobomycosis (Reif et al. 2006). Spatial variation was previously found to affect the prevalence of lobomycosis in a population of bottlenose dolphins from Florida, with the most environmentally impacted area showing a greater number of cases (Murdoch et al. 2008). However, this potential connection between the presence of contaminants and the occurrence of lobomycosis is still speculative and requires further investigation to allow us to use this disease as an indicator for human and/or habitat health.

In summary, our study reports cases of LLD in the small and resident population of Tursiops truncatus in Laguna, southern Brazil. The prevalence of the disease was similar to that observed in other areas, and historical data suggest that it is an endemic disease in the bottlenose dolphin population of the region. The progression of a particular case was steady for most of the monitoring period and then increased quickly for the last $30 \mathrm{~d}$, culminating with the disappearance of the LLD pair. Further studies are required to confirm the etiologic agent responsible for LLD, to investigate habitat health and to monitor the emergence of new cases in the population. In addition, such information will improve our knowledge of the real status of lobomycosis in the area and its threat to the dolphin population of Laguna.

Acknowledgements. We thank S. Ingram, K. H. Lüchmann, M. Cantor, C. Loch and 2 anonymous referees who provided important comments and contributions at different stages of this study. We also thank N. Nielsen and S. Ingram for the English version review. Finally, this study was supported by CNPq (National Counsel of Technological and Scientific Development), FAPESC (Fundação de Apoio a Pesquisa Científica do Estado de Santa Catarina), FBPN (Fundação O Boticário de Proteção à Natureza) and Idea Wild.

\section{LITERATURE CITED}

Bearzi M, Rapoport S, Chau J, Saylan C (2009) Skin lesions and physical deformities of coastal and offshore common bottlenose dolphins (Tursiops truncatus) in Santa Monica Bay and adjacent areas, California. Ambio 38:66-71

Bermudez L, Van Bressem MF, Reyes-Jaimes O, Sayegh AJ, Paniz-Mondolfi AE (2009) Lobomycosis in man and lobomycosis-like disease in bottlenose dolphin, Venezuela. Emerg Infect Dis 15:1301-1303
Beyer HL (2004) Hawth's analysis tools for ArcGIS. Available at www.spatialecology.com/htools

Burdett Hart L, Wells RS, Adams JD, Rotstein DS, Schwacke LH (2010) Modeling lacaziosis lesion progression in common bottlenose dolphins Tursiops truncatus using longterm photographic records. Dis Aquat Org 90:105-112

Burt WH (1943) Territoriality and home range concepts as applied to mammals. J Mammal 24:346-352

Caldwell DK, Caldwell MC, Woodard JC, Ajello L, Kaplan W, McLure HM (1975) Lobomycosis as a disease of the Atlantic bottlenosed dolphin (Tursiops truncatus Montagu, 1821). Am J Trop Med Hyg 24:105-114

Constantine R (2001) Increased avoidance of swimmers by wild bottlenose dolphins (Tusiops truncatus) due to longterm exposure to swim-with-dolphin tourism. Mar Mamm Sci 17:689-702

Cowan DF (1993) Lobo's disease in a bottlenose dolphin (Tursiops truncatus) from Matagorda Bay, Texas. J Wildl Dis 29:488-489

Dierauf LA, Gulland MD (2001) Handbook of marine mammal medicine. CRC Press, Boca Raton, FL

Flores PAC, Bazzalo M, da Silva LZ, Wells RS (2005) Evidência de residência individual e ocorrência de lesões epidérmicas em golfinhos Tursiops truncatus na Baía Norte, SC, Brasil. In: Anais do III Congresso Brasileiro de Mastozoologia, Aracruz, 2005. Universidade Federal do Espírito Santo \& Sociedade Brasileira de Mastozoologia

Geraci JR, Ridgway SH (1991) On disease transmission between cetaceans and humans. Mar Mamm Sci 7:191-194

Haubold EM, Cooper CR, Wen JW, McGinnis MR, Cowan DF (2000) Comparative morphology of Lacazia loboi (syn. Loboa loboi) in dolphins and humans. Med Mycol 38:9-14

Kiszka J, Van Bressem MF, Pusineri C (2009) Lobomycosislike disease and other skin conditions in Indo-Pacific bottlenose dolphins Tursiops aduncus from the Indian Ocean. Dis Aquat Org 84:151-157

Lahvis GP, Wells RS, Kuehl DW, Stewart JL, Rhinehart HL, Via CS (1995) Decreased lymphocyte responses in freeranging bottlenose dolphins (Tursiops truncatus) are associated with increased concentrations of PCBs and DDT in peripheral blood. Environ Health Perspect 103:67-72

Lehner PN (1996) Handbook of ethological methods. Cambridge University Press, Cambridge

Lima MC, Giacomelli MB, Stüpp V, Roberge FD (2001) Especiação de cobre e chumbo em sedimento do Rio Tubarão (SC) pelo método Tessier. Quim Nova 24:734-742

Mann J, Connor RC, Barre LM, Heithaus MR (2000) Female reproductive success in bottlenose dolphins (Tursiops sp.): life history, habitat, provisioning, and group-size effects. Behav Ecol 11:210-219

Meurer AZ, Netto SA (2007) Seasonal dynamics of benthic communities in a shallow sublitoral site of Laguna estuarine system (South Brazil). Braz J Aquat Sci Technol 11: $53-62$

> Migaki G, Valerio MG, Irvine BA, Graner FM (1971) Lobo's disease in an Atlantic bottle-nosed dolphin. J Am Vet Med Assoc 159:578-582

Moreno IG, Ott PH, Tavares M, Oliveira LR and others (2008) Mycotic dermatitis in common bottlenose dolphins (Tursiops truncatus) from southern Brazil, with a confirmed record of lobomycosis disease. Paper SC/60/DW1 presented to the IWC Scientific Committee, Santiago, May 2008. Available at www.iwcoffice.org/_documents/sci_ com/SC60docs/SC-60-DW1(colour).pdf

Murdoch ME, Reif JS, Mazzoil M, McCulloch SD, Fair PA, Bossart GD (2008) Lobomycosis in bottlenose dolphins (Tursiops truncatus) from the Indian River Lagoon, Florida: 
estimation of prevalence, temporal trends, and spatial distribution. EcoHealth 5:289-297

Paniz-Mondolfi AE, Sander-Hoffman L (2009) Lobomycosis in inshore and estuarine dolphins. Emerg Inf Dis 15. Available at www.cdc.gov/EID/content/15/4/672.htm

Powell RA (2000) Animal home ranges and territories and home range estimators. In: Boitani L, Fuller TK (eds) Research techniques in animal ecology: controversies and consequences. Columbia University Press, New York, NY, p 65-110

Reif JS, Mazzoil MS, McCulloch SD, Varela RA, Goldstein JD, Fair PA, Bossart G (2006) Lobomycosis in Atlantic bottlenose dolphins from the Indian River Lagoon, Florida. J Am Vet Med Assoc 228:104-108

Reif JS, Peden-Adams MM, Romano TA, Rice CD, Fair PA, Bossart GD (2009) Immune dysfunction in Atlantic bottlenose dolphins (Tursiops truncatus) with lobomycosis. Med Mycol 47:125-135

Rodriguez-Toro G (1993) Lobomycosis. Int J Dermatol 32: 324-332

Ross PS (2002) The role of immunotoic environmental contaminants in facilitating the emergence of infectious diseases in marine mammals. Hum Ecol Risk Assess 8:277-292

Rotstein DS, Burdett LG, McLellan W, Schwacker L and others (2009) Lobomycosis in offshore bottlenose dolphins (Tursiops truncatus), North Carolina. Emerg Infect Dis 15: 588-590

Scherer M, Ferreira C, Mudat J, Cataneo S (2006) Urbanização e gestão do litoral centro-sul do estado de Santa Catarina. Desenvolv Meio Amb 13:31-50

Simões-Lopes PC, Daura-Jorge FG (2008) Os parceiros da sobrevivência. Editora Insular, Florianópolis

Simões-Lopes PC, Fabian ME (1999) Residence patterns and site fidelity in bottlenose dolphins, Tursiops truncatus (Montagu) (Cetacea, Delphinidae) off Southern Brazil. Rev Bras Zool 16:1017-1024

Simões-Lopes PC, Ximenez A (1993) Annotated list of the cetaceans of Santa Catarina coastal waters, southern Brazil. Biotemas 6:67-92

Editorial responsibility: Michael Moore, Woods Hole, Massachusetts, USA
Simões-Lopes PC, Paula GS, Xavier FM, Scaramelo AC (1993) First case of lobomycosis in bottlenose dolphin on Southern Brazil. Mar Mamm Sci 9:329-331

Simões-Lopes PC, Fabián ME, Menegheti JO (1998) Dolphin interactions with the mullet artisanal fishing on Southern Brazil: a qualitative and quantitative approach. Rev Bras Zool 15:709-726

Symmers WS (1983) A possible case of Lobo's disease acquired in Europe from a bottle-nosed dolphin (Tursiops truncatus). Bull Soc Pathol Exot Filiales 76:777-784

Taborda PR, Taborda VA, McGinnins MR (1999) Lacazia loboi gen. nov., comb. nov., the etiologic agent of lobomycosis. J Clin Microbiol 37:2031-2033

Van Bressem MF, Van Waerebeek K, Flach L, Reyes JC and others (2007) A preliminary overview of skin and skeletal diseases and traumata in small cetaceans from South American waters. Lat Am J Aquat Mamm 6:7-42

Van Bressem MF, Van Waerebeek K, Flach L, Reyes JC, and others (2008) Skin diseases in cetaceans. Paper SC/60/ DW8 presented to the IWC Scientific Committee, Santiago, May 2008. Available at www.iwcoffice.org/_documents/sci_com/SC60docs/SC-60-DW8.pdf

> Van Bressem MF, Santos MO, Oshima JE (2009) Skin diseases in Guiana dolphins (Sotalia guianensis) from the Paranaguá estuary, Brazil: a possible indicator of a compromised marine environment. Mar Environ Res 67:63-68

Wilson B, Thompson PM, Hammond PS (1997) Skin lesions and physical deformities in bottlenose dolphins in the Moray Firth: population prevalence and age-sex differences. Ambio 26:243-247

Wilson B, Arnold H, Bearzi G, Fortuna CM and others (1999) Epidermal diseases in bottlenose dolphins: impacts of natural and anthropogenic factors. Proc R Soc Lond B Biol Sci 266:1077-1083

Worton BJ (1989) Kernel methods for estimating the utilization distribution in home range studies. Ecology 70 : 164-168

Würsig B, Jefferson PA (1990) Methods of photo-identification for small cetaceans. Rep Int Whaling Comm 12:43-52

Submitted: April 6, 2010; Accepted: September 27, 2010

Proofs received from author(s): January 12, 2011 